JURNAL PENDIDIKAN DAN KELUARGA

Vol. 11 No. 02, 2019 Page 174-182

DOI: https://doi.org/10.24036/ipk/vol11-iss02

available at http://jpk.ppj.unp.ac.id/index.php/jpk/index

\title{
PENGARUH MOTIVASI TERHADAP PRESTASI KERJA DI DAIMA HOTEL PADANG
}

\author{
Redamasari $^{1}$, Yuliana ${ }^{2}$ \\ ${ }^{1,2}$ Program Studi Manajemen Perhotelan \\ Fakultas Pariwisata dan Perhotelan \\ Universitas Negeri Padang \\ Email: redamasari01@gmail.com
}

Abstract

This research originated from the Industrial Field Experience at Daima Hotel Padang. The author found problems, related to employee work performance and lack of work motivation. This study aims to analyze the effect of work motivation on work performance in Daima Hotel Padang. This type of research is quantitative with a causal assosiative approach. The population in this study were employees of Daima Hotel Padang. The sample in this study used a purposive sampling technique with a total sample of 46 people, namely employees who already had work performance assessments. Data analysis techniques using data description and simple linear regression test using the SPSS Computer Program version 16.00. Research results show that: Work motivation is in the good category (52.17\%), Job Performance is in the quite good category (58.69\%) and the simple linear regression test results obtained $\mathrm{R}$ Square value of 0.118. Meaning that motivation significantly influences work performance employees at $11.8 \%$ and $88.2 \%$ are influenced by other factors.

Keywords: Motivation, Job Performance, Employees

\begin{abstract}
Abstrak
Penelitian ini berawal dari Pengalaman Lapangan Industri di Daima Hotel Padang. Penulis menemukan permasalahan, terkait dengan prestasi kerja karyawan dan motivasi kerja yang kurang. Penelitian ini bertujuan untuk menganalisis pengaruh motivasi kerja terhadap prestasi kerja di Daima Hotel Padang. Jenis penelitian ini adalah kuantitatif dengan pendekatan assossiatif kausal. Populasi dalam penelitian ini adalah karyawan Daima Hotel Padang. Sampel dalam penelitian ini menggunakan teknik purposive sampling dengan jumlah sampel 46 orang yaitu karyawan yang sudah memiliki penilaian prestasi kerja. Teknik analisis data menggunakan deskripsi data dan uji regresi linear sederhana dengan menggunakan Program Komputer SPSS versi 16.00. Hasil penelitan
\end{abstract}

This is an open access article distributed under the Creative Commons 4.0 Attribution License, which permits unrestricted use, distribution, and reproduction in any medium, provided the original work is properly cited. (O2017 by author and Universitas Negeri Padang. 
menunjukkan bahwa: Motivasi kerja berada pada kategori baik $(52,17 \%)$, Prestasi Kerja berada pada kategori cukup baik $(58,69 \%)$ dan hasil uji regresi linear sederhana diperoleh nilai $\mathrm{R}$ Square 0,118.Artinya motivasi secara signifikan mempengaruhi prestasi kerja karyawan sebesar $11,8 \%$ dan $88,2 \%$ dipengaruhi faktor lain.

Kata Kunci: Motivasi,Prestasi Kerja, Karyawan

\section{Pendahuluan}

Pada era globalisasi industri perhotelan saat ini mengalami perkembangan yang sangat pesat dan juga bersaing dalam mendapatkan keuntungan yang besar. Menurut Sulastiyono (2011:5), "Hotel adalah suatu perusahaan yang dikelola oleh pemiliknya dengan menyediakan pelayanan makanan, minuman dan fasilitas kamar untuk tidur kepada orangorang yang melakukan perjalanan dan mampu membayar dengan jumlah yang wajar sesuai dengan pelayanan yang diterima tanpa adanya perjanjian khusus". Perusahaan tidak akan berjalan dengan lancar tanpa adanya sumber daya manusia. Menurut Sutrisno (2009: 3), "Sumber daya manusia adalah satu-satunya sumber daya yang memiliki akal perasaan, keinginan, keterampilan, pengetahuan, dorongan, daya, dan karyan(rasio, rasa dan karsa)". Sumber daya manusia merupakan aspek terpenting yang mempengaruhi dan berperan penting dalam melakukan operasional. Dalam mengelola sumber daya manusia pihak manajemen sebaiknya memberikan sebuah prestasi kepada karyawan terhadap hasil kerja yang telah dicapai. Menurut Mangkunegara (2015: 17), "Prestasi kerja adalah hasil kerja yang dicapai oleh seseorang dalam melaksanakan dan menyelesaikan pekerjaan yang dibebankan kepadanya". Dengan indikator dari prestasi kerja yaitu: kuantitas, kualitas, pelaksanaan tugas dan tanggung jawab. Menurut HRD Daima (2019) indikator prestasi kerja yaitu penampilan kerja dan sikap kerja. Di dalam mencapai prestasi kerja karyawan banyak faktor yang menentukan. Menurut Keith Davis (dalam Mangkunegara 2017: 67) faktorfaktor yang mempengaruhi prestasi kerja salah satunya adalah motivasi.

Menurut Barelson dan Steiner (dalam Sunyoto 2015: 10), "Motivasi adalah suatu usaha sadar untuk mempengaruhi perilaku seseorang supaya mengarah tercapainya tujuan organisasi”. Motivasi membicakan tentang bagaimana cara mendorong semangat kerja seseorang agar mau bekerja dengan memberikan secara optimal kemampuan dan keahlian guna mencapai tujuan organisasi. Adapun indikator dari motivasi menurut Hartatik (2014: 164) yaitu: 1) kebutuhan fisiologis 2) kebutuhan rasa aman dan keselamatan 3) kebutuhan sosial 4) kebutuhan penghargaan 5) kebutuhan aktualisasi diri. Berkaitan dengan hal tersebut, banyak industri perhotelan saat ini yang berkembang di Kota Padang dan juga membutuhkan sumber daya yang berprestasi. Salah satunya yaitu Daima Hotel Padang,yang merupakan hotel bintangtiga (***) yang terletak di jantung Kota Padang, dengan kapasitas 93 kamar, yaitu 48 kamar superior, 38 kamar deluxe, dan 7 kamar famili. Hotel Daima terletak di Jalan Jenderal Sudirman No.17 Padang.Phone :+62 (0751) 892700 Fax : +62 (0751) 892701 Padang. Dalam pengelolaan dan organisasi sebuah hotel terdapat beberapa departemen yang ada di Daima Hotel Padang yaitu Departement Front Office (FO), 
Departement Food \& Beverage (FB), Departement Housekeeping (HK), Departement Accounting, Departement Human Resource (HRD), Departement Sales \& Marketing, DepartemenEngineering, dan Secretary Bord Of Direction.

Table 1 Jumlah Karyawan Daima Hotel Padang

\begin{tabular}{lll}
\hline No. & Departemen & Jumlah Karyawan \\
\hline 1. & General Manager & 1 Orang \\
\hline 2. & Food \& Beverage Service & 5 Orang \\
\hline 3. & Food \& Beverage Product & 9 Orang \\
\hline 4. & Front Office & 10 Orang \\
\hline 5. & Housekeeping & 11 Orang \\
\hline 6. & Engineering & 8 Orang \\
\hline 7. & Sales \& Marketing & 3 Orang \\
\hline 8. & Human Resources Department & 1 Orang \\
\hline 9. & Accounting & 8 Orang \\
\hline Jumlah & 56 Orang \\
\hline
\end{tabular}

Sumber : HRD Daima Hotel Padang (2019)

Berdasarkan Pengalaman Lapangan Industri 2 pada bulan Juli-Desember 2018. Penulis menemukan masalah yang berkaitan dengan indikator prestasi karyawan yaitu adanya karyawan yang tidak bertanggung jawab yaitu salah satu karyawan back office accounting yaitu account receivable yang lalai dalam melakukan pekerjaan seperti dalam penagihan pembayaran tamu yang sebagaimana sudah ditugaskan oleh perusahaan namun pekerjaan itu sangat lama dan sudah diingatkan berulang kali oleh chief accounting. Hal tersebut mengakibatkan service karyawan terlambat sehingga karyawan lain merasa kurang semangat untuk bekerja. Masalah ini juga dikuatkan dengan nilai prestasi karyawan yang diperoleh sebanyak 58,7\% tergolong rendah (Sumber:HRD Daima Hotel Padang(2019).

Masalah berikutnya banyaknya karyawan yang datang terlambat, dapat dilihat pada tabel berikut ini:

Table 2 Data Absensi Karyawan Di Daima Hotel Padang Juni-Desember 2018

\begin{tabular}{lllll}
\hline No & Bulan & Jumlah Karyawan & Terlambat & Terlambat lebih dari 3x \\
\hline 1 & Juni & 55 & 97 & 9 \\
\hline 2 & Juli & 55 & 97 & 7 \\
\hline 3 & Agustus & 55 & 85 & 10 \\
\hline 4 & September & 55 & 73 & 7 \\
\hline 5 & Oktober & 55 & 100 & 7 \\
\hline 6 & November & 55 & 55 & 2 \\
\hline 7 & Desember & 55 & 80 & 8 \\
\hline
\end{tabular}

Sumber: HRD Daima Hotel Padang (2019)

This is an open access article distributed under the Creative Commons 4.0 Attribution License, which permits unrestricted use, distribution, and reproduction in any medium, provided the original work is properly cited. (C2017 by author and Universitas Negeri Padang. 
Berdasarkan tabel di atas dapat dilihat bahwa absensi karyawan Daima Hotel Padang mengalami peningkatan keterlambatan lebih dari 3x setiap bulannya. Hal ini membuktikan bahwa masih adanya karyawan yang datang tidak tepat waktu. Masalah ini berkaitan dengan prestasi kerja karyawan.

Permasalahan selanjutnya terkait dengan indikator prestasi kerja yaitu kuantitas, berdasarkan pengamatan selama Pengalaman Lapangan Industri 2 penulis menemukan masalah petugas room attendant yang tidak menyelesaikan pekerjaan tepat waktu. Hal ini dilihat dari tidak tercapainya target dalam membersihkan kamar, seperti seorang room attendant yang diberikan tugas membersihkan kamar sebanyak 25 kamar dalam satu hari, namun masih sering target tercapai hanya 20 kamar, mengakibatkan terlambatnya waktu pulang dan dibebankan kepada shift selanjutnya. Kemudian masalah lainnya penulis menemukan tidak adanya promosi jabatan untuk karyawan yang telah bekerja lama di sana sehingga tidak adanya jenjang karir yang jelas.masalah ini terjadi pada saat penulis melakukan Praktek Kerja Lapangan Industri dimana salah satu karyawan Front Office keluar karena ada masalah pribadi, kemudian HRD merekrut karyawan untuk front office diambil dari luar tidak merekrut karyawan yang sudah lama bekerja disana sehingga tidak ada terjadinya turnover pada karyawan. Masalah selanjutnya tidak ada fasilitas loker untuk karyawan sehingga karyawan membawa barang bawaanya ke dalam office yang menyebabkabkan sempitnya tempat bekerja seperti gambar di bawah ini:

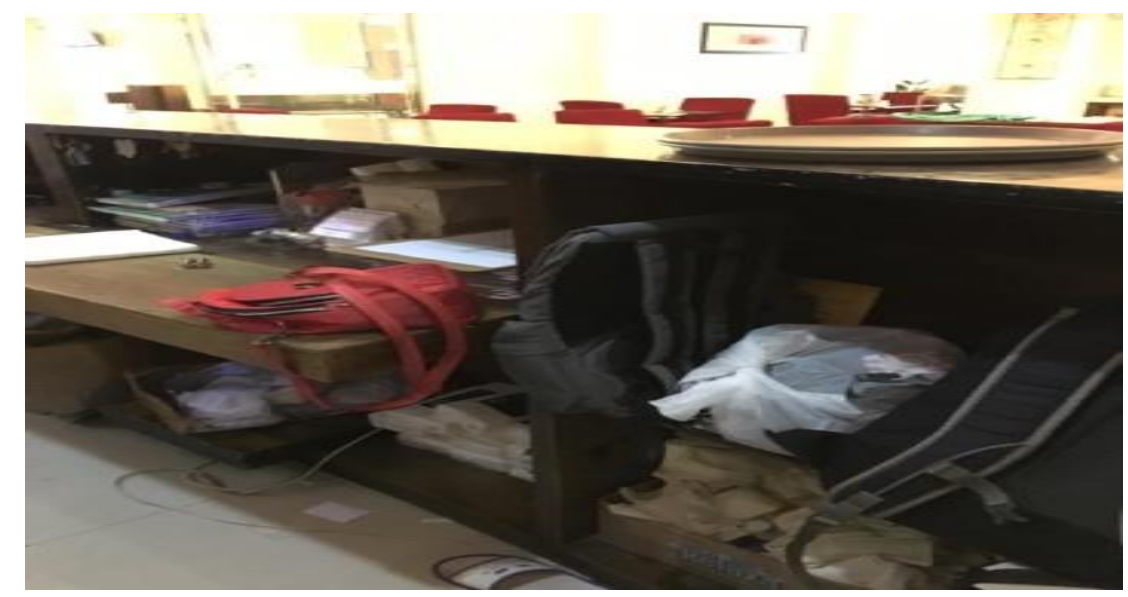

Gambar 1. Bukti Barang Bawaan Karyawan yang dibawa ke Office

Pentingnya penelitian ini dilakukan karena apabila prestasi kerja yang dilihat dari penampilan kerja dan sikap kerja rendah diasumsikan akan berdampak rendahnya produktifitas kerja yang nantinya akan berpengaruh terhadap hotel, disamping itu motivasi karyawan rendah diduga akan berpengaruh pada prestasi kerja. Tujuan dari penelitian ini adalah untuk menganalisis motivasi terhadap prestasi kerja karyawan, ditinjau dari dua variabel yaitu variabel motivasi kerja dengan indikator yaitu: kebuthan fisiologis, kebutuhan rasa aman dan keselamatan kerja, kebuthan sosial, kebutuhan penghargaan, kebutuhan aktualisasi diri, selanjutnya variabel prestasi kerja dengan 2 indikator yaitu: penampilan kerja dan sikap kerja. 


\section{Metode}

Jenis penelitian dalam penelitian ini digolongkan kepada penelitian kuantitatif dengan pendekatan asosiatif kausal. Populasi dalam penelitian ini adalah karyawan yang bekerja di Daima Hotel Padang berjumlah 55 orang dengan teknik pengambilan sampel menggunakan proposive sampling yaitu teknik pengambilan data dengan pertimbangan tertentu. kriteria yang digunakan dalam penelitian ini yaitu karyawan yang sudah memiliki nilai prestasi kerja sejumlah 46 sampel. Data dalam penelitian ini menggunakan data primer, diperoleh dari menyebarkan angket atau kuesioner kepada karyawan yang bekerja di Favehotel Padang, terdiri dari 25 pertanyaan yang telah diuji validitas dan reliabilitasnya dengan hasil semua item pertanyaan dinyatakan valid dengan nilai reabilitas 0,694 .

Data motivasi kerja dan prestasi kerja diuji dengan uji regresi linear sederhana dengan rumus: $\mathbf{Y}=\mathbf{a}+\mathbf{b x}$ dan untuk menyatakan besar atau kecilnya pengaruh variabel $\mathrm{X}$ terhadap $\mathrm{Y}$ menggunakan rumus koefisien determinasi yaitu: $\mathbf{K p}=\mathbf{r}^{2} \mathbf{x} \mathbf{1 0 0 \%}$ dengan bantuan program SPSS versi 16.00 .

\section{Hasil Dan Pembahasan}

\section{Variabel Motivasi Kerja}

Pada variabel motivasi ini, data diperoleh dari hasil penyebaran kuesioner yang terdiri dari 25 pertanyaan kepada 46 orang karyawan di Daima Hotel Padang. Hasil penelitian menunjukkan bahwa terdapat sebanyak 36,95\% karyawan memiliki motivasi kerja sangat baik. Sebanyak 52,17\% karyawan memiliki motivasi kerja baik. Dan 10,86\% motivasi kerja karyawan tergolong cukup baik.

Table 3 Distribusi Frekuensi Data Variabel Motivasi Di Daima Hotel Padang

\begin{tabular}{llll}
\hline Kategori & Rentang Skor & Frekuensi & Persentase \% \\
\hline Sangat Baik & $\geq 93,17$ & 17 & 36,95 \\
\hline Baik & $83,35-<93,17$ & 24 & 52,17 \\
\hline Cukup & $66,65-<83,35$ & 5 & 10,86 \\
\hline Buruk & $49,95-<66,65$ & 0 & 0 \\
\hline Sangat Buruk & $<49,95$ & 0 & 0 \\
\hline Jumlah & & 46 & 100 \\
\hline
\end{tabular}

Sumber:Hasil Olahan Data (2019)

\section{Variabel Prestasi Kerja}

Data Variabel prestasi kerja karyawan diperoleh dari HRD Coordinator berdasarkan appraisal score yang di ambil dari 46 responden. Berdasarkan data tersebut dapat dilihat bahwa $41,30 \%$ nilai prestasi karyawan baik, dan sebagian besar (58,69\%) karyawan memiliki nilai prestasi kerja cukup baik. Sebagaimana terlihat pada tabel 5 berikut ini:

Table 4 Distribusi Frekuensi Data Variabel Prestasi Kerja Di Daima Hotel Padang

This is an open access article distributed under the Creative Commons 4.0 Attribution License, which permits unrestricted use, distribution, and reproduction in any medium, provided the original work is properly cited. $\odot 2017$ by author and Universitas Negeri Padang. 


\begin{tabular}{llll}
\hline Kategori & Rentang Skor & Frekuensi & Persentase \% \\
\hline Sangat Baik & $91-100$ & 0 & 0 \\
\hline Baik & $81-90$ & 19 & 41,30 \\
\hline Cukup Baik & $71-80$ & 27 & 58,69 \\
\hline Kurang Baik & $60-70$ & 0 & 0 \\
\hline Jumlah & & 46 & 100 \\
\hline
\end{tabular}

Sumber:HRD Daima Hotel Padang (2019)

\section{Uji Persyaratan Analisis}

Uji persyaratan analisis dibutuhkan untuk menilai apakah data penelitian ini normalitas, ,homogenitas dan linearitas.

\section{Uji Normalitas}

Hasil uji normalitas menunjukkan bahwa nilai hasil signifikansi motivasi sebesar 0,651 dan prestasi kerja karyawan sebesar 0,484, yang mana taraf signifikansi > 0,05 sehingga dapat diartikan bahwa variabel motivasi dan prestasi kerja karyawan terdistribusi normal. Sebagaimana terlihat pada tabel 6 berikut:

Table 5 Hasil Uji Normalitas Variabel Motivasi Terhadap Prestasi Kerja di Daima Hotel Padang

\begin{tabular}{|c|c|c|c|}
\hline \multicolumn{4}{|c|}{ One-Sample Kolmogorov-Smirnov Test } \\
\hline & & Motivasi & Prestasi_Kerja \\
\hline $\mathrm{N}$ & & 46 & 46 \\
\hline \multirow[t]{2}{*}{ Normal Parameters $^{\mathrm{a}}$} & Mean & 92.39 & 80.48 \\
\hline & \multicolumn{2}{|c|}{ Std. Deviation 7.243} & 5.210 \\
\hline \multirow[t]{3}{*}{ Most Extreme Differences } & Absolute & .108 & .124 \\
\hline & Positive & .108 & .124 \\
\hline & Negative & -.076 & -.123 \\
\hline Kolmogorov-Smirnov Z & & .736 & .838 \\
\hline Asymp. Sig. (2-tailed) & & .651 & .484 \\
\hline
\end{tabular}

a. Test distribution is Normal.

\section{Uji Homogenitas}

Hasil uji homogenitas menunjukkan bahwa Diperoleh nilai sig. 0,059 dengan taraf signifikansi $>0,05$. Artinya nilai signifikansi data lebih besar dari taraf ketentuan yang telah ditetapkan. Dapat dikatakan bahwa data motivasi dan prestasi kerja karyawan berasal dari populasi yang mempunyai variance yang sama atau data bersifat homogen. Sebagaimana terlihat pada tabel 7 berikut:

Table 6 Hasil Uji Homogenitas Variabel Motivasi Terhadap Prestasi Kerja di Daima Hotel Padang 


\begin{tabular}{llll}
\hline Levene Statistic & df1 & df2 & Sig. \\
\hline 2.053 & 10 & 33 & .059 \\
\hline
\end{tabular}

\section{Uji Linearitas}

Hasil uji linearitas linearitas di peroleh nilai sig 0,579 dengan taraf signifikansi $>0,05$. Sehingga dapat disimpulkan bahwa terdapat Pengaruh yang linear pada kedua variabel tersebut. Sebagaimana terlihat pada tabel 8 berikut ini:

Table 7 Hasil Uji Linearitas Variabel Motivasi Terhadap Prestasi Kerja di Daima Hotel Padang

\begin{tabular}{|c|c|c|c|c|c|c|c|}
\hline \multicolumn{8}{|l|}{ ANOVA Table } \\
\hline & & & $\begin{array}{l}\text { Sum of } \\
\text { Squares }\end{array}$ & Df & $\begin{array}{l}\text { Mean } \\
\text { Square }\end{array}$ & $\mathrm{F}$ & Sig. \\
\hline \multirow{5}{*}{$\begin{array}{l}\text { Prestasi_Kerja } \\
\text { Motivasi }\end{array}$} & \multirow{3}{*}{$\begin{array}{l}\text { Between } \\
\text { Groups }\end{array}$} & (Combined) & 634.428 & 22 & 28.838 & 1.130 & .386 \\
\hline & & Linearity & 144.156 & 1 & 144.156 & 5.648 & .026 \\
\hline & & $\begin{array}{l}\text { Deviation from } \\
\text { Linearity }\end{array}$ & 490.273 & 21 & 23.346 & .915 & .579 \\
\hline & \multicolumn{2}{|c|}{ Within Groups } & 587.050 & 23 & 25.524 & & \\
\hline & \multicolumn{2}{|l|}{ Total } & 1221.478 & 45 & & & \\
\hline
\end{tabular}

\section{Pengujian Hipotesis}

Berdasarkan hasil uji regresi linear sederhana dengan nilai F sebesar 5.888 dengan taraf signifikansi sebesar $0,019<0,05$, artinya motivasi berpengaruh terhadap prestasi kerja karyawan di Daima Hotel Padang, kemudian diperoleh nilai koefisien sebesar 0,247 dengan nilai sig. $0,019<0,05$, artinya setiap peningkatan sebesar 1 satuan motivasi akan meningkatkan 0,247 satuan prestasi kerja karyawan di Daima Hotel Padang, maka $\mathrm{H}_{\mathrm{a}}$ diterima dan Ho ditolak terdapat pada tabel 9 berikut ini:

Table 8 Koefisien Determinasi (R square)

\begin{tabular}{lllll}
\hline \multicolumn{3}{l}{ Model Summary } \\
\begin{tabular}{lllll} 
Model & $\mathrm{R}$ & $\mathrm{R}$ Square & Adjusted R Square & Std. Error of the Estimate \\
\hline 1 & $.344^{\mathrm{a}}$ & .118 & .098 & 4.948 \\
\hline a. Predictors: (Constant), Motivasi & \\
\hline
\end{tabular} \\
\hline
\end{tabular}

Berdasarkan tabel 8 di atas diperoleh nilai $R$ square $=0,118$ artinya kontribusi atau pengaruh variabel motivasi terhadap prestasi kerja karyawan adalah $11,8 \%$, sedangkan $88,2 \%$ ditentukan oleh faktor lain.

Pembahasan

This is an open access article distributed under the Creative Commons 4.0 Attribution License, which permits unrestricted use, distribution, and reproduction in any medium, provided the original work is properly cited. $\odot 2017$ by author and Universitas Negeri Padang. 


\section{Motivasi}

Berdasarkan hasil penelitian, dapat dijelaskan bahwa dari 46 orang sampel untuk variabel motivasi diperoleh 24 responden menunjukkan kategori Baik dengan persentase $62,17 \%$.

Motivasi di Daima Hotel Padang dilihat dari kelima indikator motivasi: kebutuhan fisiologis, kebutuhan rasa aman dan keselamatan, kebutuhan sosial, kebutuhan penghargaan, kebutuhan aktualisasi diri. Sehingga dapat disimpulkan bahwa motivasi di Daima Hotel Padang memiliki kategori Sangat Baik. Hasil analisis data variabel penelitian tentang motivasi yang dilihat dari lima indikator dikategorikan sangat baik dan satu indikator di kategorikan Baik. Tetapi pada indikator kebuthan fisiologis masih terdapat 19,56\% karyawan dalam kategori cukup, pada indikator kebutuhan rasa aman terdapat 36,5\% karyawan dalam kategori cukup, dan pada indikator kebutuhan sosial terdapat 23,91\% karyawan dalam kategoru Baik. dan pada indikator kebutuhan penghargaan terdapat 4,34\% karyawan dalam kategoru cukup, dan pada indikator kebutuhan aktualisasi diri terdapat 43,47\% karyawan dalam kategoru Baik. Sesuai dengan pendapat Jerald Greenberg dan Robert a. Baron (dalam Wibowo 2014:322) motivasi adalah serangkaian proses yang membangkitkan, mengarahkan dan menjaga perilaku manusia menuju pada pencapaian tujuan.

\section{Prestasi Kerja Karyawan}

Berdasarkan hasil penelitian, dapat dijelaskan bahwa dari 46 orang sampel untuk variabel Kinerja Karyawan diperoleh 27 responden menunjukkan kategori Cukup dengan persentase 58,69\%. Hasil analisis data variabel prestasi kerja karyawan dikategorikan cukup baik. Hasibuan (2010 :94), "Prestasi kerja merupakan hasil kerja yang dicapai seseorang dalam melaksanakan tugas-tugas yang dibebankan kepadanya yang didasarkan atas kecakapan, pengalaman, dan kesungguhan serta waktu".

\section{Pengaruh Motivasi Terhadap Prestasi kerja Karyawan di Daima Hotel Padang}

Hasil penelitian uji hipotesis yang digunakan untuk mengetahui derajat pengaruh $\left(\mathrm{r}_{\mathrm{xy}}\right)$ antara Motivasi Terhadap Prestasi kerja Karyawan di Daima Hotel Padang dengan menggunakan analisis SPSS 16.00 diperoleh Hasil pengujian pengaruh motivasi terhadap prestasi kerja karyawan di Daima Hotel Padang adalah 11,8\%. sedangkan 88,2\% dipengaruhi oleh faktor individu dan faktor lingkungan, dengan nilai $\mathrm{F}$ hit 5.888 dengan signifikansi $0,019 \leq 0,05$ artinya variabel motivasi dapat menjelaskan variabel prestasi kerja karyawan secara signifikan.

Sesuai dengan hasil penelitian Theodora Yatipai (2015) dengan judul "Pengaruh Motivasi terhadap Prestasi Kerja Karyawan Studi Pada PT POS Indonesia Tipe C Manado". Hasil penelitian menunjukkan adanya korelasi atau hubungan yang signifikan antara motivasi terhadap prestasi kerja karyawan sebesar 46,5\%. Selanjutnya hasil penelitian Dewi (2016) dengan judul "Pengaruh Motivasi terhadap Prestasi Kerja Pegawai Pada Badan Perencanaan Pembangunan Daerah Kota Bandung” menunjukkan bahwa terdapat hubungan yang sangat kuat antara motivasi dengan prestasi kerja sebesar $66,7 \%$. Mengingat bahwa motivasi berpengaruh terhadap prestasi kerja karyawan maka sangat perlu meningkatkan motivasi kerja supaya meningkat pula prestasi kerja karyawan. 


\section{SIMPULAN DAN SARAN}

\section{Simpulan}

Motivasi di Daima Hotel Padang secara keseluruhan termasuk kedalam kategori Baik dengan persentase 67,12\%, kemudian Prestasi Kerja Karyawan di Daima Hotel Padang secara keseluruhan termasuk kedalam kategori Cukup dengan persentase sebesar 58,69\% Selanjutnya diperoleh hasil pengujian hipotesis, yaitu pengaruh yang signifikan antara motivasi terhadap prestasi kerja karyawan di Daima Hotel Padang sebesar 11,8\%. sedangkan $88,2 \%$ dipengaruhi oleh faktor lain diluar penelitian ini.

\section{Saran}

Disarankan kepada pihak manajemen Daima Hotel Padang untuk meningkatkan motivasi karyawan dan meningkatkan motivasi dalam bidang rasa aman dan keselamatan agar prestasi kerja karyawan dapat ditingkatkan dan untuk meningkatkan nilai prestasi kerja karyawan seperti memberikan pelatihan dan pemberian motivasi agar prestasi kerja karyawan dapat ditingkatkan.

\section{DAFTAR PUSTAKA}

Hartatik, Indah Puji, 2014. Buku Praktik Mengembangkan SDM. Yogyakarta:Laksana.

HRD Daima Hotel, 2019. Penilaian Karyawan 2018. Daima Hotel Padang

Hasibuan. 2010. Manajemen Sumber Daya Manusia. Jakarta:PT Bumi Aksara

Mangkunegara. 2017. Manajemen Sumber Daya Manusia Perusahaan. Bandung:PT Remaja Rosdakarya

Sulastiyono, Agus. 2011. Manajemen Penyelenggaraan Hotel. Bandung: Alfabeta

Sunyoto, Danang. 2015. Penelitian Sumber Daya Manusia. Yogyakarta:PT Buku Seru

Sutrisno, Edy. 2009. Manajemen Sumber Daya Manusia. Jakarta:Kencana Prenada media Group

Wibowo. 2014. Manajemen Kinerja. Jakarta:PT. Raja grafindo 